Revista Eletrônica do Mestrado em Educação Ambiental

\title{
Da colonialidade à sociedade de risco: a posição da Educação Ambiental em frente a esse diálogo
}

\author{
Elisângela Lazzaril ${ }^{1}$ \\ FURG
}

ORCID https://orcid.org/0000-0002-0926-0015

Sérgio Botton Barcellos ${ }^{2}$

FURG

ORCID http://orcid.org/0000-0002-6935-4398

\begin{abstract}
Resumo: $O$ presente artigo apresenta uma reflexão sobre a questão socioambiental e sua interface com as questões políticas no processo de construção do conhecimento. O texto foi escrito na forma de ensaio, utilizando uma análise teórica da modernidade, sociedade de risco e Educação Ambiental a partir de três artigos deste campo: A política da sociedade de risco, de Ulrich Beck (2010); Colonialidade do poder, eurocentrismo e América Latina, de Aníbal Quijano (2005) e Educação Ambiental e Epistemologia Crítica, de Carlos Frederico B. Loureiro (2015). Nesse contexto, buscamos refletir a relação entre colonialidade e formação da sociedade de risco na linha do tempo pós-industrial articulando com o debate acerca da Educação Ambiental crítica.
\end{abstract}

Palavras-chave: Educação Ambiental; Colonialidade e Sociedade de risco

\section{De la coloniedad a la sociedad del riesgo: la posición de la educación ambiental frente a este diálogo}

Resumen: El presente trabajo muestra un pensamiento sobre la cuestión socioambiental y sus relaciones con las cuestiones políticas en el proceso de construcción del conocimiento. El texto está escrito en forma de ensayo utilizando un análisis teórico de la modernidad, la sociedad del riesgo y la educación ambiental a partir de tres documentos en este campo: Politica de sociedad

\footnotetext{
${ }^{1}$ Licenciada em Ciências Biológicas pela Universidade Federal do Rio Grande - FURG. Mestranda em Educação Ambiental pela FURG. e-mail: lislazzari@hotmail.com.

${ }^{2}$ Doutor em Ciências Sociais em Desenvolvimento, Agricultura e Sociedade pela Universidade Federal do Rio de Janeiro (2014). Professor adjunto da Universidade Federal do Rio Grande - FURG. e-mail: sergiobbarcellos@hotmail.com.

Rev. Eletrônica Mestr. Educ. Ambient. Rio Grande. v. 37, n. 3. Seção especial: XI EDEA - Encontro e Diálogos com a Educação Ambiental. p. 349-364. mai./ago. 2020. 
de riesgo, por Ulrich Beck (2010); Colonialidad del poder, eurocentrismo e América Latina, por Anibal Quijano (2005) e Educación Ambiental y epistemologia critica, por Carlos Frederico B. Loureiro (2015). En este contexto, buscamos reflejar la relación entre la colonialidad y la formación de la sociedad del riesgo en la línea del tiempo posindustrial que se fusiona con una educación ambiental crítica.

Palabras clave:Educación Ambiental; Colonialidad y Sociedad de riesgo.

\title{
From coloniality to risk society: the position of Environmental Education in front of this dialogue
}

\begin{abstract}
The present paper shows a thought on the socio-environmental question and its relations with politic questions in the knowledge construction process. The text is written in the form of academic essay using a theoretical analysis of modernity, risk society and environment education from three papers in this field: The risk society policy, of Ulrich Beck (2010), Coloniality and power: eurocentrism and Latin America of Anibal Quijano (2005) and Environmental Education and critical epistemology, of Carlos Frederico B. Loureiro (2015). In this context, we seeks to reflect the relationship between coloniality and formation of the risk society in the line of the pos-industrial time merging with a critical environmental education.
\end{abstract}

Keywords: Environmental Education; Coloniality and Risk society.

\section{Introdução}

As discussões acerca da pós colonialidade são recentes na produção científica. Na década de 1960 começou a aumentar a produção científica de estudos, que cunharam o termo decolonialidade para designar e refletir sobre o processo pós-independência dos países colonizados no mundo ao longo do século XIX e XX. Este movimento ocorreu principalmente nos Estados Unidos e Inglaterra por pesquisadoras e pesquisadores oriundos de países asiáticos, da África e após latino-americanos, ainda limitando a produção de conhecimento a partir dos colonizadores, sobre os colonizados, um processo, que mesmo com diferentes discursos, se mantém por mais de 500 anos na história da humanidade.

No final do século XX e início do século XXI surgiu uma onda de estudos sulistas a respeito da colonização e do período pós-colonização em que vivemos, com o termo colonialidade, introduzido por Aníbal Quijano (1997). Evidenciado as relações de poder dos países da América Latina, introduzidas com a colonização que continuam sendo disseminadas atualmente, sobre novas ordens societárias. O estudo a respeito desse tema, nos países colonizados é tardio por conta do processo histórico vivido. A partir dos anos 1960 quando os países do Sul passaram pela ditadura militar, à produção de conhecimentos críticos a hegemonia era censurada. Após, a redemocratização do

Rev. Eletrônica Mestr. Educ. Ambient. Rio Grande. v. 37, n. 3. Seção especial: XI EDEA - Encontro e Diálogos com a Educação Ambiental. p. 349-364. mai./ago. 2020. 
país, a partir dos anos 1980, os países sulistas começaram a produzir materiais teóricos de contribuição para esse debate, sendo que uma das maneiras de descolonizar as teorias e a ciência é produzindo nossa própria ciência e teoria.

A colonialidade, a partir de produções científicas latinoamericanas, ganha um novo sentido, a colonização deixa de ser um fato isolado historicamente em um período e passa a ser refletido como intrínseco a formação da modernidade. A modernidade com a industrialização e seu modo de produção, reprodução e utilização da natureza, passa a ser percebida como um dos motores da crise socioambiental evidenciada no século XX e XXI.

A urgência e centralidade da crise socioambiental ganha evidência no período pós-industrial, por uma tomada de consciência do modelo de produção capitalista, que, em consequência de sua forma de uso do meio ambiente, acarreta em uma série de problemas socioambientais, evidenciados pela ciência e sentidos pela população, tendo como marco, do início de um pensamento mais recente a respeito da crise, o acidente de Chernobyl $^{3}$. Os aspectos considerados negativos do progresso determinam cada dia mais o futuro da natureza (BECK 2010, p. 229), como a tecnologia que opera o período industrial e se mostra como um dos motores da destruição da natureza, e a ciência, enquanto neutralizada, sem um víeis de denúncia política tende a contribuir com a crise. Assim, o debate acerca da crise socioambiental em que vivemos que forma uma sociedade de risco, segundo o conceito de Beck (2010), é de grande importância, pois pode auxiliar a pensar a complexidade da crise socioambiental, um novo modo de (des)envolvimento e novas configurações da sociedade.

Buscamos o embasamento em Loureiro (2015) e em sua concepção de Educação Ambiental crítica, para elucidar esse tema e ensaiar um entrelaçamento com o conceito de colonialidade e sociedade de risco. A Educação Ambiental crítica surge em contraposição das vertentes conservadoras, nos anos 1990, em uma corrente que abrange a Educação Ambiental popular, que analisa processos emancipatórios, de gestão ambiental e variações do mesmo tema (LAYRARGUES, 2012 p. 403). Esta linha que destacadamente declara o pertencimento a uma filiação político-pedagógica, percebendo a educação como um ato político e para uma formação política que questiona a realidade em que vivemos. Consideramos, que, por mais que ela traga

\footnotetext{
${ }^{3}$ Acidente nuclear ocorrido em Chernobyl Ucrânia, em 1986, quando a explosão de um reator nuclear liberou cerca de 100 vezes mais radiação que as bombas de Hiroshima e Nagasaki, deixando um número de mortes, a longo prazo, de aproximadamente cem mil pessoas. (Greenpeace, 2011). Considerado por autores, como Ulrich Beck (2010), o marco do pensamento a respeito da crise em nível mundial.

Rev. Eletrônica Mestr. Educ. Ambient. Rio Grande. v. 37, n. 3. Seção especial: XI EDEA - Encontro e Diálogos com a Educação Ambiental. p. 349-364. mai./ago. 2020. 
reflexões epistemológicas de grande repercussão acadêmica, a mesma ainda é uma perspectiva teórica restrita majoritariamente ao campo acadêmico, principalmente em nível das pós-graduações e alguns nichos da blogsfera na internet.

Considerando a influência das relações sociais e políticas na organização da sociedade atual, torna-se relevante um adensamento teórico sobre as questões que cercam os problemas socioambientais vividos pelas sociedades modernas. Assim, por meio deste ensaio buscamos refletir acerca da construção de epistemologias do conhecimento, com o objetivo de problematizar e relacionar os conceitos: sociedade de risco, colonialidade do poder e Educação Ambiental, a partir das obras citadas acima.

A pergunta norteadora para a elaboração deste ensaio é: De que forma a colonialidade como processo social e histórico está contida na formação da teoria da sociedade de risco e como a Educação Ambiental crítica pode ser uma lente analítica para análise da atual crise socioambiental no século XXI?

Neste intento o ponto de partida deste ensaio será dado por meio de uma revisão bibliográfica do conceito de colonialidade, da formação do capitalismo, com suas causas, efeitos e consequências no modo de viver das sociedades modernas, tendo como base o texto: Colonialidade do poder, eurocentrismo e América Latina, de Aníbal de Quijano (2005). Em um segundo momento, o conceito da sociedade de risco, a partir do texto: A política da Sociedade de risco, de Ulrich Beck (2010), será analisado em sua formação e a reflexividade política que emergem no seio da crise socioambiental. Por último será discutido a Educação Ambiental, a partir das reflexões de Loureiro (2015) em seu texto: Educação Ambiental e Epistemologia Crítica, evidenciando a alienação do trabalho, o pensamento crítico e nossa relação com o ambiente.

Assim, buscamos construir um diálogo entre a Educação Ambiental como um meio de análise da crise socioambiental, oriunda da sociedade moderna, a partir da reflexividade política e da promoção da produção de conhecimento para além da influência eurocêntrica.

\section{Colonialidade constitutiva}

As produções científicas tiveram origem na Europa do século XIV ao XVI, a partir de ideologias que se opunham às influências do dogma religioso, abordando uma ideia racional a partir da vida prática. Conjuntamente e influente em um período 
histórico com o início da modernidade ocorreu à formação da cultura industrial ocidental e a colonização dos países da América Latina. Segundo Quijano (2005), o processo histórico e social de construção das sociedades modernas com a ciência e a industrialização foi uma forma eurocêntrica de construção do conhecimento cuja elaboração sistemática não era o modo de pensar geral na Europa, mas constituiu uma perspectiva que se tornou hegemônica a partir do século XVI.

Esta perspectiva hegemônica foi disseminada por todos os países colonizados demarcando relações de poder e dominação, tanto materiais, como subjetivas. Considerando outros povos sem origem europeia como "não modernos" ou "não civilizados", mas povos passíveis de "civilizar", foi uma das crenças geradas para justificar a exploração do trabalho e da dominação cultural. Reconhecendo o conhecimento eurocentrado, como verdade única, excluindo outras formas de ser, poder e saber, que se produziu conhecimento para a dominação e colonização dos povos na América do Sul, África e algumas nações na Ásia. De acordo com Lander (2000 apud Assis 2014 p. 615)

Ao tornar perceptível outras formas de se ver a modernidade, o paradigma colonialidade-modernidade clarifica que os diferentes discursos históricos (evangelização, civilização, modernização, desenvolvimento e globalização) procuram sustentar a concepção arbitrária de que há um padrão civilizatório que é, simultaneamente, superior e normal.

A colonialidade é um conceito introduzido pelo sociólogo peruano Anibal Quijano, no final dos anos 1980 e no início dos anos 1990. Quijano (1997; 2005) cunhou esse conceito como algo que transcende as particularidades do colonialismo histórico e que não desaparece com a independência ou descolonização mas ganha continuidade com a formação do moderno-sistema-mundo ${ }^{4}$.

A colonialidade dos países europeus sobre os países da América Latina é o início da globalização e do capitalismo moderno, segundo as palavras de Quijano (2005), "o capitalismo mundial foi desde o início colonial/moderno e eurocentrado" (QUIJANO 2005. p. 120). A dominação colonial, de proposição de poder, teve fundamento em dois eixos primordiais: a ideia de superioridade de raça, tendo como justificativa a ciência; e o controle do trabalho para o mercado mundial (QUIJANO, 2005). A dominação de raça e do mercado mundial é uma forma de se estabelecer as relações de poder da

${ }^{4}$ Termo introduzido por Immanuela Wallerstein em uma teoria pós-marxista, baseia-se na divisão inter-regional e transnacional do trabalho e resulta na divisão do mundo em países centrais e periféricos (QUIJANO, 2005).

Rev. Eletrônica Mestr. Educ. Ambient. Rio Grande. v. 37, n. 3. Seção especial: XI EDEA - Encontro e Diálogos com a Educação Ambiental. p. 349-364. mai./ago. 2020. 
sociedade moderna. A colonialidade do poder tem como princípio o controle: da natureza; economia; autoridade; gênero; sexualidade; subjetividade e conhecimento. Assim, a colonização produziu relações sociais de dominação de raça, gênero, trabalho e natureza que são percebidas como reflexo na sociedade atual nas relações patriarcais, racistas, de separação de classes e da crise socioambiental.

$\mathrm{Na}$ perspectiva da colonialidade, as antigas hierarquias coloniais, que foram agrupadas na relação europeu versus não europeu, continuaram arraigadas e enredadas na divisão internacional do trabalho e na acumulação do capital à escala global (ASSIS, 2014 p. 614).

O controle do trabalho é uma forma de controle de grupos sociais (povos originários e africanos escravizados), na América Latina. A escravidão no contexto colonizatório europeu a partir do século XVI serviu para produzir mercadorias para o mundo gerando um novo modelo de organização e controle do trabalho, o capitalista, que se sustenta com a divisão e a exploração de uma classe social sobre outra.

Em um recorte de gênero e raça, no trabalho, é possível perceber os reflexos da escravidão no processo histórico pós-independência na América. Por exemplo, o censo de 1890, nos Estados Unidos da América (EUA), mostrou que em 32 dos 48 estados, o trabalho doméstico era a ocupação predominante tanto de homens como de mulheres negras, em sete de cada dez estados, havia mais pessoas negras trabalhando em funções domésticas do que em todas as ocupações juntas (DAVIS 2016, p. 101). Outro exemplo recente é o trabalho doméstico no Brasil que é majoritariamente tomado por mulheres negras, entre 2004 e 2011, a proporção de mulheres negras ocupadas nos serviços domésticos no país cresceu de 56,9\% para $61,0 \%$, ao passo que entre as mulheres não negras observou-se uma redução de 4,1\%, com a participação correspondendo a 39,0\%, em 2011 (DIEESE, 2013).

Isto é, evidencia-se que a distribuição racista do trabalho no interior do capitalismo colonial/moderno manteve-se ao longo de todo período colonial (QUIJANO, 2005, p.119) considerando que ainda não nos desprendemos das correntes coloniais. Assim, a colonialidade continua presente na relação entre Estado e sociedade, entre os Estados, entre Estado e sujeitos e entre os sujeitos.

\section{A Sociedade de Risco da pós-modernidade}

Rev. Eletrônica Mestr. Educ. Ambient. Rio Grande. v. 37, n. 3. Seção especial: XI EDEA - Encontro e Diálogos com a Educação Ambiental. p. 349-364. mai./ago. 2020. 
A sociedade moderna, industrial e capitalista se constitui por sucessivas crises em seu modelo societário, as gritantes diferenças de classe, raça, de gênero e do campo/cidade e atualmente mais uma dessas crises é evidenciada dada a continuidade e a ampliação das desigualdades sociais e econômicas em escala global. A reprodução de dualismos do período colonial: racional/irracional, primitivo/civilizado moderno/não moderno; rural/urbano - como justificativa de dominação - perpetuam nas sociedades modernas e contribuem para a crise socioambiental.

As transformações no mundo sob a égide do "progresso" como forma de pensamento que direciona o processo histórico das sociedades a partir dos diferentes estágios do capitalismo aparecem cada vez mais com os reflexos ambientais. Os riscos ambientais gerados no primeiro período industrial são diferentes dos vividos no segundo período industrial, por conta dos avanços tecnológicos e científicos. Segundo Beck (2010) os riscos encontram-se: ilimitados, sem possibilidade de atribuição a um indivíduo e não podem ser objeto de compensação, sendo que atingem uma totalidade global e não podem mais ser medidos em um tempo e espaço. Mesmo assim, é perceptível que os riscos ainda são sentidos por uma parcela da população com mais intensidade, como com as comunidades tradicionais, do campo, ribeirinhas, seringueiras, da floresta, que acabam sentindo os riscos ambientais de forma mais intensa pois dependem das relações intrínsecas com ambiente e os elementos da natureza disponíveis para sua sobrevivência.

Entre os Estados, como com os países da América Latina, que são usados na exploração de minérios, que são exportados para países da Europa e da América do norte, para a produção de tecnologias que são vendidas posteriormente aos países do sul. Essa relação evidencia a exploração de territórios, mão de obra e do ambiente dos países do Sul, para o manufaturamento nos países do Norte.

Ulrich Beck, sociólogo alemão, influenciado pela onda de movimentos teóricos nos anos 1980, formulou o conceito: Sociedade de Risco para denominar a crise enfrentada pela sociedade moderna e seu modo de produção e reprodução. Segundo a análise deste conceito feita por Leite (2011) a sociedade de risco é uma tomada de consciência do modelo de produção, em uma fase seguinte do período industrial (LEITE, 2011 p. 151). Segundo Beck (2010) os riscos da sociedade moderna são racionais, o sistema de produção tem compreensão dos riscos, mas não os tornam visíveis, desconhecendo suas causas e não os tomando como responsabilidade.

Rev. Eletrônica Mestr. Educ. Ambient. Rio Grande. v. 37, n. 3. Seção especial: XI EDEA - Encontro e Diálogos com a Educação Ambiental. p. 349-364. mai./ago. 2020. 
Assim, as causas dos problemas ambientais são globais, mas tendem a ser reduzidas a particulares (BECK, 2010 p. 243), ou ainda acusando o crescimento demográfico, enquanto países de primeiro mundo passam o problema para países de terceiro mundo (Beck, 2010). O autor sugere a necessidade de implementação dos mecanismos de imputabilidade da culpa, em todos os níveis e em todos os meios, com: visibilidade, pela ciência, dos reais agentes do problema ambiental; círculos de discussão transdisciplinares; reforma do direito penal; responsabilidades regionais; convenções regionais. Isto é, a partir da causa dos conflitos, será possível chegar aos responsáveis e cobrar destes a sua responsabilidade ao dano. A responsabilidade precisa ser evidenciada e tomada por agentes para a resolução dos problemas ambientais, pois tende há uma difusão da responsabilidade aos indivíduos, como um todo, como se o consumo individual pudesse ser comparado à produção industrial em termos de problemas ambientais. Ou seja, ao invés do governo incentivar a diminuição da produção de produtos excedentes, os mercados capitalistas, junto ao governo promovem campanhas influenciando o uso de produtos recicláveis, a compra de produtos orgânicos, campanhas eco-capitalistas, apropriadas pelo capital para gerirem sua manutenção, o que não resolve o problema da crise socioambiental, mas desvia o discurso da origem e da realidade do problema.

Os conflitos ambientais são relações de disputa por elementos da natureza, interesses sobre o uso, exploração e distribuição dos mesmos que estão em constante transformação e que não deixará de acontecer mesmo com a mudança do sistema societário. Enquanto o homem transformar e utilizar a natureza, sendo estas fundamentais para a vida humana, os conflitos existirão, a questão colocada por Beck (2010) é que "a partir do momento em que a sobrevivência de todos está em causa, os conflitos ecológicos estão suficientemente fundados moralmente e socialmente" (BECK, 2010, p. 241). Uma das principais questões relacionadas aos conflitos é a distribuição destes em conjunto com os riscos, segundo Beck (2010), a uma possível solução para os conflitos quando o dano é inegável "é mantê-lo o mais difuso possível, imprevisível e concentrá-lo em um número limitado de vítimas” (BECK, 2010 p. 234). Assim, o conflito não pode ser considerado "um problema" em si, pois é um tipo de sociabilidade constitutiva das sociedades, mas sim a marginalização, a pauperização e até a eliminação física dos grupos com formas de viver não dominantes. 
Os movimentos de justiça ambiental iniciados nos EUA, com o movimento contra o racismo ambiental ${ }^{5}$, evidenciam o direcionamento histórico dos riscos ambientais para áreas marginalizadas das cidades e demais territórios, e consequentemente para a população periférica, com recorte de raça (negros e latinos) e classe (operariado, camponeses, povos e comunidades tradicionais). É perceptível que o mesmo ocorre em nível mundial, como descrito acima, pela transferência do contingente e da demanda da extração e exploração de recursos naturais para os países do Sul, e uso deste pelos países do "norte global". De certa forma, observa-se com a alcunha de "neoextrativismo" uma das formas de exercício da colonialidade no século XXI e sua influência atual na utilização, manejo e vivência com a natureza, na organização social, na classificação e hierarquização por aspectos de raça, classe e determinadas funções econômicas mundialmente.

Para Beck (2010) a questão central da sociedade de risco está na reflexividade política sobre o risco. A reflexividade política segundo Beck (2010) é responsável pelo êxito dos movimentos ecologistas. Caracteriza-se no momento em que a massa da população toma conhecimento a respeito dos riscos e perigos causados pelos danos ambientais do sistema societário hegemônico. Tornando-os visíveis e com sua devida preocupação, abre a possibilidade de analisar e até questionar o sistema vigente e sua relação com a questão socioambiental, tornando possível a formação de pressões e organização para a cobrança da resolução dos conflitos socioambientais. Os riscos não são neutros e "somente através de símbolos culturalmente significados e publicamente encenados que o cotidiano ficará atento aos perigos" (BECK, 2010 p. 231). Isto é, a visibilidade de alguns riscos e a invisibilidade de outros não é por acaso, assim os meios de comunicação se tornam essenciais na reflexividade política da população.

\section{A era da informação}

A percepção acerca das questões socioambientais tendem a ficar reduzidas a informações consideradas simplificadas e a ações individuais, não sendo percebidas como um todo em contexto histórico, político, econômico, social, de produção e reprodução do sistema vigente. "Ler a realidade de forma crítica nos ajuda a explicar as

\footnotetext{
${ }^{5}$ Este movimento teve início das discussões nos anos 70 e consolidação nos anos 90. Coloca uma pauta política nos movimentos ambientalistas, evidenciando que em sociedades desiguais, são os grupos racialmente descriminados e de baixa renda, que arcam com a carga mais pesada dos danos ambientais gerados pelo desenvolvimento (LAYS, 2012). Rev. Eletrônica Mestr. Educ. Ambient. Rio Grande. v. 37, n. 3. Seção especial: XI EDEA - Encontro e Diálogos com a Educação Ambiental. p. 349-364. mai./ago. 2020. 
relações sociais mercantilizadas e alienantes que perpassam a forma hegemônica de organizar a sociedade" (TREIN 2012, apud LOUREIRO, 2015, p.316). O pensamento crítico tem como característica racionalmente questionar toda a verdade socialmente apresentada e refutar todo pensamento que se dissocia sociedade e natureza (LOUREIRO, 2015).

Com o advento e ampliação do acesso à internet nos anos 1990 o acesso à informação se diferencia, não há uma dependência relativa da indústria midiática para receber informações, pois nos tornamos também sujeitos da produção e procura da informação. Ao mesmo tempo surgem preocupações: quem pode e quem se torna agente da produção de informação? Qual é a informação que mais ganha relevância em meio a milhões de outras informações? Por exemplo, Terry Pratchett em uma entrevista com Bill Gates, em 1995, demostrou a sua preocupação ao colocar que, qualquer informação colocada na internet fica disponível nos mesmos termos de qualquer outra informação, existindo uma paridade na confiabilidade das informações na rede.

O termo meme, foi introduzido pelo biólogo Richard Dawkins, em seu livro: o gene egoísta. $\mathrm{Na}$ era da internet os memes tem grande destaque na distribuição de informação nas redes sociais, sua principal característica é a duplicação e proliferação, o que necessita tornar o conteúdo resumido e em uma caricatura facilitando suas chances de se espalhar. A informação científica, de leitura da realidade vivenciada é complexa, difícil de ser sintetizada em uma caricatura e contidas em um meme, tendo assim dificuldade de se espalhar na internet e de chegar as massas da população. Em 2016 o departamento da Universidade Oxford responsável pelos dicionários, escolheu a palavra Pós-verdade ${ }^{6}$ como a palavra do ano, esta evidenciada nas últimas eleições, tanto nos EUA, em 2016, como no Brasil, em 2018, onde as redes sociais foram vitais para a divulgação política.

A proliferação de fatos inverídicos é um fenômeno das redes sociais, aonde, reduzidas a memes, a realidade torna-se reduzida a mitos. Nesse contexto é possível perceber a reflexividade política em uma linha tênue, aonde a informação chega as massas da população conforme sua capacidade de duplicação e proliferação, gerando uma sociedade de pós verdades, inclusive a partir do negacionismo científico, como a negação das mudanças climáticas.

\footnotetext{
${ }^{6}$ Post-trhut - pós verdade: relativo ou referente a circunstâncias nas quais os fatos objetivos são menos influentes na opinião pública do que as emoções e as crenças pessoais (Dicionário de Oxford, traduzido para o português.

Rev. Eletrônica Mestr. Educ. Ambient. Rio Grande. v. 37, n. 3. Seção especial: XI EDEA - Encontro e Diálogos com a Educação Ambiental. p. 349-364. mai./ago. 2020. 


\section{A Educação Ambiental}

A educação com vistas para emancipação é um meio para percebermos as possíveis relações de alienação que perpassam nossa vida no trabalho, na família e na sociedade. Sob essa perspectiva para Postone (2014) uma sociedade aonde as estruturas sociais aparecem como atemporais, naturalizadas e fetichizadas, as relações sociais ocorrem balizadas pelo trabalho alienado.

A dominação, como mostra o processo de colonialidade, esteve presente desde a formação do Brasil. Durante este processo histórico em meio às lutas, resistências e adesões os sujeitos tiveram dificuldade em reconhecer seu lugar na sociedade, na natureza e as relações que os permeiam. Conhecer é à base da consciência do mundo em que vivemos e da intervenção deste, "o ser humano precisa ser entendido como um ser criador que por meio de sua atividade no mundo, vai alterando a realidade e produzindo cultura" (LOUREIRO, 2015 p. 166).

Loureiro (2015) calcado nas ideias de Postone (2014) apresenta a ideia de que o processo de transformação social não se dá pelo agir no mundo do trabalho, ou da linguagem, mas pela superação das formas de mediação social em uma sociedade determinada historicamente (LOUREIRO 2015 p. 161). O processo colonizatório condicionou os países colonizados a produzirem e consumirem conforme a necessidade da hegemonia mundial, subjugando as necessidades locais dos seus povos.

Em relação ao descrito acima, vejamos alguns exemplos. As comunidades tradicionais, ao produzirem e comercializarem seus produtos entre suas comunidades, oriundos do ambiente em que vivem, tem potencial de gerar um processo de resistência ao mercado. Ao construírem relações de pertença do seu local no ambiente, da exploração do capital e se organizarem politicamente, estão resistindo à hegemonia, em prol da valorização dos seus saberes e fazeres cotidianos. O mesmo, por exemplo, pode ocorrer com as mulheres, ao perceberem sua condição de dominação em respeito aos homens, e criarem formas organizativas de dialogo das opressões vividas - que se assemelham - com reivindicações por paridade de gênero, no trabalho, cuidado com filhos (as) e na vida política podem formar resistências à dominação hegemônica masculina.

A Educação Ambiental crítica é colocada por Loureiro em seu livro: Sustentabilidade e Educação: um olhar da ecologia política (2012), como garantia de 
coesão e da convivência social, a fim de preparar os indivíduos para exercerem suas funções críticas e dialógicas na sociedade como para participarem efetivamente nas decisões política que dizem respeito ao seu ambiente e seu modo de vida. Desse modo, não ficando condicionados aos modos de vida ditos por uma hegemonia política que definem os modos de produção, comercialização e de felicidade - pelo consumo - da população. A quebra da hegemonia política de interesses privados questiona a exploração de classes e remete a superação da simplificação da análise da realidade que operam as engrenagens do sistema vigente.

A produção de conhecimento, enquanto produção social, não se separa da sua dimensão ideológica e de seu comprometimento de classe. O conhecimento é produzido socialmente nas relações sociais, coletivas, com o ambiente em que vivemos e formamos/transformamos por relações sociais e educativas que podem gerar a promoção da igualdade e diversidade social (LOUREIRO, 2015). Sobretudo, significa a possibilidade de desnaturalizar e questionar as correntes epistemológicas e ontológicas da colonialidade, do eurocentrismo presente na subjetividade e nos nossos quereres, ou seja, começarmos a elaborar as nossas próprias questões e respostas sobre o nosso processo histórico e existencial.

Analisar a sociedade de forma dualista potencialmente distorce a compreensão da realidade e tendencialmente separa a compreensão da relação do humano com a natureza, da natureza com a cultura, do corpo com a mente, do pensamento com a ação, do conhecer com a experiência. E essa forma de existir e as relações sociais configuradas influenciam a nossa forma de ser e estar com o mundo, contribuindo para a crise socioambiental em que vivemos. A Educação Ambiental crítica a partir do conjunto de atores e movimentos sociais que a promovem propõe que para uma produção de conhecimento mais realista da natureza precisamos nos ver como parte integrante e em relação de interdependência com a natureza.

Somos muito diferentes da Europa, mas, em uma visão da colonialidade ainda nos vemos como um autorretrato da sociedade europeia e em um processo mais recente ao longo do século XX também norte americana, buscando os mesmo padrões de produção, consumo e subjetividade. Segundo Quijano (2005), dessa maneira seguimos sendo o que não somos, não conseguindo identificar nossos problemas e nossas próprias questões, muito menos resolvê-los e criar respostas ou formular outras questões. 


\section{Considerações finais}

A partir de Loureiro (2015), Quijano (1997; 2005) e Beck (2010) trazidos neste ensaio para um diálogo e reflexão acerca das questões socioambientais foi possível discutir e tecer relações entre a Educação Ambiental crítica, a colonialidade e a sociedade de risco. Isto é, analisamos a influência do processo de colonização na formação das sociedades modernas e como estes contribuem para a formação da sociedade de risco, bem como a Educação Ambiental crítica como alternativa na produção de conhecimento, resistência e questionamento do capitalismo.

A dominação da natureza e a partir disso a produção de mercadorias, de autoridade, da economia, das subjetividades, do conhecimento, das relações de gênero, raciais e de classe foram às premissas européias para a produção das bases da sociedade em que vivemos na atualidade. Esta com seus modos de produção e reprodução material e subjetiva influenciou na configuração da crise socioambiental evidenciada no final do século XX.

A manutenção do processo industrial de formação do capital é oriunda da colonização por uma massificação e globalização da hegemonia dominante dos modos de produção, material e subjetiva do capitalismo. A crise é além do capitalismo, é no mínimo também questionando a colonialidade. Invisibilizar a influência desse sistema vigente, na contribuição da crise socioambiental é negar os reais agentes e causas da crise, é invisibilizar as comunidades periféricas mais afetadas, é manter os mesmo padrões de dominação e poder do período colonial. Esse debate também não se esgota na troca de sistema societário com o desmanche do capitalismo. Segundo Loureiro (2015) os problemas do mundo não surgiram do capitalismo e também não vão acabar com o fim deste, são questões postas pela contemporaneidade e precisam ser enfrentadas concretamente.

A dominação da economia que consequentemente leva a dominação da autoridade em uma sociedade aonde o capital é o que controla a produção também é percebida na distribuição de terras. Do coronelismo ${ }^{7}$ ao mandonismo $^{8}$ os donos das terras estão em constante sucessão entre oligarquias e os modos de produção são ditos

\footnotetext{
${ }^{7}$ Relações semelhantes ao mandonismo, determinada historicamente na Primeira República 1889 a 1930 (Carvalho, 1997).

${ }^{8}$ Característica da política tradicional, que sempre esteve presente na política brasileira, aonde o mandão, por conta de seu controle em algum recurso estratégico, exerce um domínio sobre a população, que é impedida de ter livre acesso ao mercado e a sociedade política (Carvalho, 1997).

Rev. Eletrônica Mestr. Educ. Ambient. Rio Grande. v. 37, n. 3. Seção especial: XI EDEA - Encontro e Diálogos com a Educação Ambiental. p. 349-364. mai./ago. 2020. 
por esta hegemonia, por uma produção em massa, de commodities do agronegócio (soja, milho, cana de açúcar, arroz, silvicultura etc) e da mineração (ferro, cobre, zinco, nióbio etc) para exportação da produção de diversas mercadorias.

Essas relações de dominação tendencialmente levam a uma sociedade desigual e que tem como um dos seus desdobramentos a crise socioambiental. Quando poucos sujeitos tem acesso a maior parte da riqueza, oriunda do período colonial, e a partir disso mantém relações de poder e dominação material e subjetiva, tendo o controle da produção e reprodução do sistema vigente, fica evidente a desigualdade social estrutural do país.

As relações do trabalho alienado contribuem na manutenção da colonialidade e são premissas para a manutenção do capitalismo. Os espaços são escassos e pouco promovidos para reflexão e formulação de um pensamento das relações de produção e consumo vigentes, das relações coletivas e com o meio. Os movimentos e organizações sociais que atuam como resistência tem grande potencial de mudança da realidade de dominação e poder impostas no período colonial e mantidas no pós industrialismo na América, África e Ásia.

Vislumbrar um novo sistema societário implica refletir sobre novas formas de organização política, de trabalho, de meios de comunicação, de movimento, reconhecimento e planejamento local do povo para o povo. A Educação Ambiental crítica enquanto uma formulação teórica que tem em seus princípios epistemológicos a emancipação, uma gestão participativa e popular é um modo de se pensar em uma nova organização societária. Para Loureiro (2015) as organizações coletivas têm papel fundamental na formação de sociedades mais igualitárias e justamente organizadas. A formação de grupos de resistência, como os movimentos sociais, grupos organizados de mulheres, os povos tradicionais, oriundos do processo de marginalização são essenciais para questionar os ideais da sociedade de risco.

Mas também não podemos ver a educação como a salvação, colocando toda a responsabilidade nesta para a superação da crise socioambiental. Concordando com Loureiro (2015) a Educação Ambiental não pode se converter em uma espécie de messianismo, para não recairmos nos mesmos princípios coloniais. Mas também pensar em outro modelo de sociedade, de nossa condição enquanto país colonizado perpassa por uma transformação nos modos de produção de conhecimento, o que perpassa pela educação. Como Freire coloca em sua terceira carta pedagógica "se a educação sozinha 
não transforma a sociedade, sem ela tampouco a sociedade muda" (FREIRE, 2000, p.67).

Cabe salientar que a descrição, reflexão e análise elaborada neste ensaio não tem a intenção de esgotar o assunto, ou chegar a algum resultado, mas de trazer subsídios para reflexões e pesquisas futuras, contribuindo com as reflexões teóricas acerca da colonialidade do poder, sociedade de risco e a Educação Ambiental sob uma perspectiva crítica.

\section{Referências}

ASSIS, Wendell Ficher Teixeira. Do colonialismo à colonialidade: expropriação territorial na periferia do capitalismo. Caderno CRH, Salvador, v. 27, n. 72, p. 613-627, Set/Dez 2014

BECK, Ulrich. A Política na Sociedade de risco. Idéias. Campinas (SP)|n. 1|nova série $\mid 2^{\circ}$ semestre. 2010.

CANOTILHO, José Joaquim; MORATO LEITE, José Rubens. Direito constitucional ambiental brasileiro. São Paulo: Saraiva, 2011.

CARVAlHO, Murilo José. Mandonismo, Coronelismo, Clientelismo: Uma Discussão Conceitual. Rio de Janeiro 1997 v. 40 n. 2

DAVIS, Angela. Mulheres, raça e classe. Tradução Heci Regina Candiani - 1. Ed. São Paulo: Boitempo, 2016.

DAWKINS, Richard. O gene egoísta. São Paulo. Companhia das Letras. 2017

DIEESE (Departamento Intersindical de estatísticas e estudos socioeconômicos). $\mathbf{O}$

Emprego doméstico no Brasil. N 68. Agosto de 2013. Retirando em <https://www.dieese.org.br/estudosetorial/2013/estPesq68empregoDomestico.pdf> acesso em julho 2019

FREIRE, Paulo Reglus Neves. Pedagogia da indignação: cartas pedagógicas e outros escritos. Apresentação de Ana Maria Araújo Freire. Carta-prefácio de Balduino A. Andreola. São Paulo: Editora UNESP, 2000.

IBOPE. Instituto Brasileiro de Opinião e Estatística. 2011.

IBGE. Instituto Brasileiro de Geografia e Estatística. 2017.

Rev. Eletrônica Mestr. Educ. Ambient. Rio Grande. v. 37, n. 3. Seção especial: XI EDEA - Encontro e Diálogos com a Educação Ambiental. p. 349-364. mai./ago. 2020. 
LAYRARGUES, Philippe Pomier. Muito prazer, Sou a educação ambiental, seu novo objeto de estudo sociológico. Anais do I ${ }^{\circ}$ Encontro da ANPPAS. 2002.

LAYS, Helena Paes e Silva. Ambiente e justiça: sobre a utilidade do conceito de racismo ambiental no contexto brasileiro, e-cadernos ces [Online], 17 | 2012.

LOUREIRO, Frederico Carlos. Sustentabilidade e Educação: um olhar da ecologia política. São Paulo. 2012. Cortez Editora. (Coleção questões da nossa época v. 39).

LOUREIRO, Frederico Carlos, Educação Ambiental e Epistemologia Crítica, Rev. Eletrônica Mestr. Educ. Ambient. E-ISSN 1517-1256, v. 32, n.2, p.159-176, jul./dez. 2015

OXFORD, Dictionaries. 2016. Retirado em <https://languages.oup.com/word-of-theyear/word-of-the-year-2016>

POSTONE, Moishe. Tempo, trabalho e dominação social. São Paulo: Boitempo, 2014.

QUIJANO, Aníbal. Colonialidad del Poder, Cultura y Conocimiento en América

Latina. In: Anuário Mariateguiano. Lima: Amatua, v. 9, n. 9, 1997

QUIJANO, Anibal. Colonialidade do poder, eurocentrismo e América Latina. En libro: A colonialidade do saber: eurocentrismo e ciências sociais. Perspectivas latinoamericanas. Edgardo Lander (org). Colección Sur Sur, CLACSO, Ciudad Autónoma de Buenos Aires, Argentina. Setembro 2005. p.227- 278.

GREENPEACE BRASIL. Vitimas de Chernobyl. 18 mar. 2011. Disponível em: <http://www.greenpeace.org/brasil/pt/Greenblog/vtimas-de-chernobyl/blog/33819/>. Acesso em: 22 de julho de 2019.

Submetido em: 24-01-2020.

Publicado em: 21-08-2020.

Rev. Eletrônica Mestr. Educ. Ambient. Rio Grande. v. 37, n. 3. Seção especial: XI EDEA - Encontro e Diálogos com a Educação Ambiental. p. 349-364. mai./ago. 2020. 